\title{
Student Run Biology Workshop: An Educational and Transformative Experience in Biosciences
}

\author{
Katerina Kedraka (corresponding author) \\ Department of Molecular Biology \& Genetics \\ Democritus University of Thrace-Greece \\ Dragana, Fotis Kafatos Build., Alexandroupolis, 68100 Greece \\ Tel: 30-255-103-0617Ｅ-mail: kkedraka@mbg.duth.gr
}

Received: August 23, 2018 Accepted: September 17, 2018 Published: September 24, 2018

doi:10.5296/ijld.v8i3.13544

URL: https://doi.org/10.5296/ijld.v8i3.13544

\begin{abstract}
In this article we argue that integrating and self-directed knowledge across university learning can lead to critical reflections and potentially transformative learning, for both students and educators. Student Run Biology Workshop (SRBW) is an innovative, self-directed learning project, carried out by the students of the Department of Molecular Biology \& Genetics, in the Democritus University of Thrace-Greece. Our aim was to find out whether this educational experience was a transformative experience, as well. Qualitative research method was used; data was collected in December 2017 at the end of three feedback discussions by personally-written opinion documents and proceeded through Content Analysis. Results showed that students' participation and consequently their teamwork within the SRBW energized them to face assumptions, to engage in new concerns, to adopt alternative learning practices, to gain a critical and comprehensive understanding of Biosciences and their role within the field. The experience gained by the students has led them to a review of roles, to the building of a new perception of knowledge, to co-operation, to self-management of educational activities, and, eventually, to a more emancipatory learning. But what if this SRBW project is something much more? Which are the key dilemmas concerning this emancipatory learning strategy deriving from this experience for the participant students- future Bioscientists? Furthermore, what about the dilemmas that we, their professors, faced when we saw our students fly so high -without needing us? And, as Brookfield (1996) underlined, can we critically approach our assumptions and assertions without experiencing the consequences of our actions?
\end{abstract}

Keywords: Transformative learning, self-directed learning experiences, biosciences, 
dilemmas

\section{Introduction}

In Sciences' third grade education the pedagogical interest has been lately focused on educating students to be critical and reflective. Transformative learning theory is considered one of the most proper ones, with its emphasis on changing and adapting frames of reference through critical discourse and critical reflection on content and personal assumptions (Fraser, 2015). Pennington, Simpson, McConnell, Fair and Baker (2013) in their long-term transdisciplinary research proposed a model for understanding how transformative learning occurs in cross-disciplinary collaboration and how can this lead to transformative science. They argued that engagement in cross-disciplinary collaboration within a project produces disorienting dilemmas that initiate transformative learning. Such an education focuses on critical approaches, authentic learning experiences, multiple ways to think and the formation of the professional identity of a scientist (Hamlin, 2015). However, Bissell and Lemons (2006) argue that in the field of Biosciences, higher education studies do not always encourage students to think critically.

In the context of a cognitive approach learning things are simple, since students use different individual tactics to improve their learning (Schraw, Crippen, \& Hartley, 2006), through various learning experiences and events, according to Kong (2015): simple cognitive strategies for processing information, problem solving for defining the specific path for reaching a goal and critical thinking, related to a person's ability to think reflectively and decide skillfully (Yilmaz, 2017). The interesting question though is if learning experiences during university studies in the field of Biosciences can go beyond cognitive approaches and reach critical thinking? How can Transformative Learning be activated in higher education?

Transformative Learning Theory, established by Jack Mezirow, has focused primarily on the mechanisms leading to changes in frames of reference or meaning schemes. Learning leads to transformation when an individual critically reflects on his assumptions, restructures the "frames of reference", by challenging some of his well-established fundamental notions about the self and the world (Hunter, 2012). New perspectives and changes on the frames of reference occur by interpreting learning experiences and Mezirow (2000) proposes that a new way of thinking and acting, a fresh rationale to his/her actions, occurs for the learner. In this frame, learning experiences become the shaping tool leading to reflection on bias, conflicts and dilemmas since people are usually trapped in a "cognitive system", while transformation offers a new perspective leading to new cognitive habits (Mezirow, 2009). Transformative learning experiences, thus, are the elements that trigger a shift in the way students think and act. According to Clark (1993) transformative learning "shapes people, makes them different, in a way that both themselves and others can recognize" (p. 47). Seen as a journey from learning to reflection and acting, learning becomes more integrated into the life of the learner and the mental shifts that should be made, help him/her adopt changes that are more transformative than studying facts and figures. Transformation of mental habits is deeper than merely changing one's opinions regarding aspects of a temporal or uncomfortable reality (Stafford, 2012). 
Illeris (2014) argues that the concept of transformative learning should also include the definition of "identity", as today's living is changing and evolving so rapidly that we must constantly adapt our identity to new conditions - a struggle for constant change that can only be achieved through transformative learning processes. Thus, he defines transformation as a "learning that leads to a change in the learner's identity" (Illeris, 2014, p. 40). Illeris (2015), also, notes that transformative learning when implemented in an educational context finds very good ground in a project, which offers an opportunity for rich learning experiences. When students feel that they have invested in learning through a project, they are motivated, they acquire multiple skills and understand that learning how to learn is more important than acquiring knowledge through lectures at the auditorium, a prerequisite for building their future professional identity.

Self-directed learning triggering transformational learning experiences is didactically used either in academic or mostly in vocational and professional education including internships, work placements, on-the-job training, excursions, adventure and wilderness trips, studios, laboratories, workshops, clinicals, practicums, case study approaches, action research, role plays, hypotheticals, and simulations. This kind of learning is argued that leads to transformational learning experiences, valued for example in ICT, Economics, Humanities or Health Studies, where computer simulations, case studies models, video-based activities, group discussions and syndicate methods, autobiographical writing, problem-based learning, group work, use of reflective journals and self-directed projects are common educational tools (Andresen, Boud \& Cohen, 2001). In 1990 Pintrich and De Groot examined relationships between motivational orientation, self-regulated learning, and classroom academic performance in Science and English classes. Their findings showed students developed self-efficacy, self-regulation, and use of self-directed learning strategies obtained from work on classroom assignments, leading them not only to cognitive engagement, performance and achievements but also in critical (and thus) transformative learning. White and Nitkin (2014) presenting a program developed at Simmons College, where students are challenged to tackle a pressing social issue, such as poverty or hunger, and create realistic solutions to the problem, argued that this self-directed approach harness the power of the theory of transformative learning. They report the deep and positive impact of the program on students' engagement with critical learning, personal growth, academic habits and attitudes, student leadership and initiative, and sense of community at Simmons College.

\subsection{Dilemmas}

In Transformative Learning Theory a reflective experience is supposed to trigger the exploration of biases and assumptions deriving from previous life experiences and false beliefs. The transformation process usually begins with a disorienting dilemma leading to self-reflection on these internalized assumptions, in order to reach new ways of being and thinking and eventually, of acting (Mezirow, 1990, 1997, 2000). A dilemma, therefore, could be viewed as the opportunity to critically examine meaning structures, and reveal alternatives we haven't thought until that point (Fraser, 2015). Nohl (2015) argued that a dilemma "begins when novelty, neither anticipated nor planned, breaks into life. The new occurs abruptly..." (p. 39), that is an initial step in a process based on an experience, the transformative catalyst, 
which may be a single event unexpected - or not. Dilemmas, as proposed by Kroth and Boverie, (2009), can be viewed as being imposed by the learner (these dilemmas are happening to me), or intentional (these dilemmas are happening because of me) and the speed of this discovery can be classified as evolutionary (slow) or revolutionary (immediate) (Newman, 2012).Taking into consideration that transformative learning cannot be viewed as an instant fact, the beginning of the process of transformation, may be a dilemma deriving from a project, an educational event, a training program or a new way of approaching teaching and curriculum (Cullen, Bloemker, Wyatt, \& Walsh, 2017).

Summing up, transformative thinking can only be approached as an "escape from an established mental habit, a qualitative change in the way one learns" (Kegan, 1994, p. 232). Brookfield $(1986,2000)$ focuses precisely on the liberating function of transformative learning, its critical and emancipatory dimension. Cranton (2013) argues that critical thinking requires that we have identified and then processed mental habits so that we can make changes, focusing on the importance of integrating transformative learning into higher education teaching. She suggests that university studies should offer multiple learning opportunities, which may trigger critical reflection in order to reach transformation. In the Department of Molecular Biology and Genetics such an experience was the Student Run Biology Workshop.

\subsection{What is the Student-Run Biology Workshop}

Student-Run Biology Workshop (SRBW) is a bottom-up learning initiative coming from the students of the Department of Molecular Biology and Genetics (DMBG) of the Democritus University of Thrace. Its aim is to involve the participating students in self-managed and active learning processes by exploring alternative ways of collaborating, researching, presenting and, in general, deepening their scientific knowledge and their role as future scientists within their curriculum. It is addressed to students of Biological Departments from all over Greece (and abroad), who share their keen interest for the field.

During SRBW the participant students form teams and each team undertakes the processing and public presentation of a scientific topic (ie, "Bioterrorism and biotechnology: Building non-conventional means of war", "Approaching the Two Genders: Structural Differences between Female and Male Brain", "Crime: Laboratory Techniques", "Plants with Intelligence: Brain-free Consciousness"). The fundamental axes of the process are the scientific excellence and the resourcefulness of the presentation, as well as the familiarization of the participants with the presentation to an audience in the context of a congress simulation's model. They learn through interaction and collaboration but above all, they have a good time within an atmosphere of commitment to Biology and Science.

The project is divided into three working phases: The first day is Teambuilding. Participants, under the guidance of a coordinator, learn about values such as collaboration, trust and teamwork through various games, activities and simulations. The second phase is the Working Day. Each group works on the topic it has undertaken, combining scientific and critical thinking, with the aim of creating a resourceful presentation. Finally, the third phase is the Presentation Day, when each group presents its topic to the public. 
In order to function properly, there is the SRBW Organizing Committee working throughout the year preparing and taking care of the details of SRBW. It consists of Media and Promotion Coordinators, responsible to record and promote the project in Social Media, Organizing Coordinators are responsible for organizational issues, including finding venues and sponsorship and Team Facilitation Coordinators are responsible for the coordination of the participating teams, following team facilitation standards and care of the various needs of their team. It is worth to note that the faculty of the Department of MBG is involved in the whole project only by supporting it, for example, by facilitating the adaptation of the lectures' program, proofreading of the final presentation or providing creative feedback, when requested.

\section{Method}

The current research is a small-scale study focusing on how students understand this SRBW learning experience as part of their studies at the Department of Molecular Biology \& Genetics. Research methodology follows the qualitative approach that was considered the most appropriate, because it allows an in-depth analysis and interpretation of the data, collected by the technique of free, associative written recording of the views of seven students who were participating in the two last SRBW Organizational Committees (one was a 'veteran'!), allowing them the greatest possible freedom to reveal what they consider important, the "truth" they want to report (Atkinson, 1998). The research question was: "How would you describe the learning experience you have gone through during your participation in SRBW?". Data collection took place in December 2017, after three feedback discussions between the researcher and the group of students, who accepted with great willingness to share their experience.

Data was processed by the Content Analysis method, which, using the data categorization process and classification into thematic categories with a conceptual definition, allows the content of the narrations to be translated into findings, which are then interpreted and discussed in qualitative terms. Content Analysis is considered appropriate for "decoding and interpreting written data and especially personal beliefs, attitudes, assumptions and perspectives" (Verma \& Mallick, 2004, p. 224). Data interpretation by the researcher is the most interesting and provoking - at the same time - part in a qualitative research (Kyriazi, 2006). Five categories of data were selected: Skills, attitudes and values, emotions, dilemmas and critical reflection.

\subsection{Study Constraints}

It should be noted that since this is a small-scale study and the qualitative analysis is based on the discussion of the views of seven particular students, generalization of the findings is not supported in any way. The only intention is to highlight some essential aspects regarding reflection and possible shifts on learning, as they were recorded after this educational experience of SRBW by the students of the DMBG. We also note that opinions recorded were translated from Greek; therefore, some language adjustments were necessary to reach the actual meaning of the claims. 


\section{Macrothink}

\section{Results}

The answers of the students show that, although SRBW's project at a first level can be understood as a cognitive process and experience, the scientific knowledge is not mentioned as an important element but, on the contrary, it seems that learning emphasis is on acquiring skills:

- Learning about Biology was not the main goal.

- I learned not only to manage myself, to practice my communication or diplomacy and argumentation but also to deal and share with others.

- I learned the importance of good organization and programming to manage and deal with difficult or unpredictable situations

- The skills we acquired were not the results of a lecture. They were techniques we learned by ourselves, that we practiced and evaluated their role to our success or failure.

Learning is, however, interpreted at the level of attitudes and values:

- My participation in SRBW has taught me that patience and taking responsibilities are the most important elements in succeeding.

- Thanks to interaction, I learned to overcome misunderstandings, to work and cooperate in teams, to share ideas and to struggle for the best possible result.

- I learned how to cope with people very different from me, but we managed to work smoothly and eventually, we reached a fertile result.

At the same time, SRBW triggered emotional aspects, perhaps laying interesting grounds in the biography of students -future Bioscientists:

- Aspects of ourselves that fulfilled us as future scientists and as individuals as well, were revealed.

- SRBW is what I will be always carrying with me with a big smile. I will remember, after many years, those wonderful emotional moments I shared with friends

- My personal ambition: to come as an observer at the 20th Student-Run Biology Workshop and to feel the same enthusiasm.

Some dilemmas were arisen, showing that it was really a deeply meaningful and emancipatory learning experience for the participant students: It made them critically approach assumptions, examining at the same time the consequences of their actions:

- Sometimes I wondered if I can call it learning. It is very different from everything we have experienced as "learning" so far.

- I asked myself is this Science? Is it possible to approach deep scientific knowledge on Molecular Biology and Genetics only through interaction with my fellow students? 
Through this learning experience reflective thinking emerged; this may lead to a transformation of assumptions, focused mainly on their self-image and their role as future scientists:

- Through SRBW I felt growing up, knowing myself in depth, while dealing with difficult situations.

- ..., an experience beyond Biosciences, and perhaps a challenge that helped me set goals, overcome obstacles and go out stronger and renewed, doing things I may have never thought of.

- ... you learn things about Science but also about yourself, aspects of your personality that appear only under pressure...

- SRBW is the proof that enthusiasm, passion and strong will are the most important factors that make personal as well as collective goals or aspirations to come true.

- It was a good opportunity to reflect on the "negative" elements of my character, those that need improvement.

\section{Discussion}

The findings of this small-scale study confirm both Jarvis (2004), who believes that learning is a "process of transforming the experience into knowledge, skills, attitudes, values, feelings" ( $\mathrm{p}$. 50) and Mezirow (1990), who argues that learning is based on the interpretation of an experience that is reflected on actions and reflected on values, perceptions, thoughts and feelings which, to a significant extent, are formed by the interpretation of our experiences. It seems that Illeris (2015), with his long experience in Education, has a strong point claiming that transformative learning grows best in projects, where learning experiences provide the opportunity to critically reflect and act.

This initiative seemed to generate to a cognitive struggle, a concept identified as the engine that drives highly creative thinking since knowledge, skills and concepts are acquired and mental models are subsequently transformed, a process Mezirow referred to as transformative learning (Pennington, et al, 2013). However, while initially SRBW seems as a cognitive experience, knowledge at the bioscientific field was not the key element. The learning emphasis was paid on skills' acquisition. Indeed, both Merriam (2004) and Cranton (1994) underline that education leads to changes reflecting not only on the amount of knowledge we gain, but also improvement of our skills and abilities, a change in the set of our values, of the way we communicate and socialize, changes that affect our views, and maybe our "mental habits" -the way we review and reflect on our experiences.

SRBW probably triggered a reflective process for students to begin thinking on the way they learn, they communicate, they understand their limits, thereby, they may succeed in giving space in a more comprehensive and coherent incorporation of their experiences and, subsequently, acting on the basis of their new interpretations of the world. Mezirow (1990, 2000) argues that one of the purposes of emancipatory education is to provide the learner with a sharp and in-depth understanding of his/her historical reality -his/her biography. This is achieved prospectively by the transformation of opinions ('perspective transformation'), of the 
critical reflection on the way he/she sees himself/herself and his/her relationships with others (Kegan, 2000).

SRBW could be understood as a good practice of collaborative learning, where everyone is mutually supportive and sharing emotions, opinions and experiences, testing alternatives, in other words, SRBW formed a framework within which the transforming process empowered individuals toward critical and emancipatory attitudes, as Brookfield (2000) put it. SRBW, also, seems to fulfil Zimmerman's (2008) model on self-regulating learning, a process in which the individual chooses, manages and evaluates the learning activities to which he/she is consciously involved throughout his or her life. In SRBW initially students set their goals, strategically designed their learning and regulated their motives and feelings accordingly. Then, during the performance phase, they self-monitored, by focusing on their target and performing mission-fulfilment strategies. Finally, in the self-reflection phase, they made personal judgments about what they have learned, according to the interpretations they gave to the entire learning experience. Indeed, the dimension of self-regulated learning within the SRBW project is very interesting concerning the management of learning in terms of objectives, resources, materials, methods, duration and evaluation. This ability is considered by Brookfield (1986, 2000) one of the criteria that build up our adulthood. Thus, since students have successfully gone through all the steps of the learning process autonomously and independently, they showed evidence of maturity and self-determination, a promising sign that this learning experience helped them to become critically thoughtful and autonomous individuals, who could possibly turn into active citizens interested (and promising) to bring about social change (Brookfield, 1986).

In the study we can, also, distinguish the role of the interpersonal relationships among students, as they emphasize that through SRBW's practice they learned to cooperate, confirming Illeris (2015) who argued that the achievement of academic goals can also be understood in relational terms. The students seemed to redefine their identities and their views on learning, as the experience had a result on building a 'fresh' perception of knowledge, co-operation, self-management and identity. Mezirow, in his dialogue with Dirkx (Dirkx \& Mezirow, 2006), argues that the process of critical reflection "occurs outside of awareness and may include emotional, intuitive, symbolic, imaginistic, and/or contemplative modes of learning" (p. 124). As Brookfield (1996) underlined, we cannot critically approach our assumptions without experiencing the consequences of our actions. The students' critical perceptions and dilemmas concerning learning into the field of Biosciences is "a process leading to change that is induced by experience and increases the expectation of possible improved performance and future learning" (Ambrose, Bridges, DiPietro, Lovett \& Norman, 2010, p. 3). And as Pennington et al (2013) showed, when transformative learning occurs in cross-disciplinary collaboration it can lead to transformative science.

The support of faculty is provided in the context of a broader mentoring relationship between them and the students. This relationship did not detract students from the self-management nature of the project; on the contrary, due to the trust and security they felt, positive conditions of critical processing of this learning experience were probably created, since mentors must provide security, trust, respect and codes of conduct to encourage support and transformational 
learning (Brookfield, 1986).

Regarding myself as a faculty member, I kept asking: What did I learn? What did I gain out of this? What does this mean for me working on teaching and learning fields all my life? And what did we, the faculty members of the DMBG, feel seeing our students working on this project?

First of all, I couldn't miss our students' learning maturity: they were very effective in defining goals, in using and tailoring learning strategies accordingly. I saw them motivated, with a sense of personal responsibility and control on the whole process. I was proud to see the development of their critical thinking, the setting "internal" questions to themselves, to straw through obstacles and cognitive difficulties. Finally, I concluded they could manage their learning with our support -but without us! I was wondering: do they really need us? To which extend? And what could this mean for me, as a professor? I deeply felt it is high time to face my own dilemmas, the ones that Dirkx (2001) claims that reveal a kind of "burning bush" feeling. Such experiences offer us an opportunity to reflect on and reexamine aspects of our careers that we may not have thought about for many years, if ever. Mezirow claimed in 1978: "There are certain challenges or dilemmas in everyday life that cannot be resolved by the usual way we handle problems - that is, by simply learning more about them or learning how to cope with them more effectively. Life becomes untenable, and we undergo significant phases of reassessment and growth in which familiar assumptions are challenged and new directions and commitments are charted" (p. 101). Indeed, for me, as a professor, SRBW was a good chance to engage in a deeper questioning on my professional role, as Cranton and King (2003) suggest, my contribution to students' learning. Should I welcome the challenge or turn away from it? Do I really want -or not- to change my assumptions and beliefs that may question at a fundamental level my existing ways of thinking, believing, working or feeling as a faculty member?

\section{Conclusions}

Student-Run Biology Workshop (SRBW) is a project fully undertaken by the students of the Department of Molecular Biology and Genetics of the Democritus University of Thrace, aiming to involve undergraduate students in the field of Biosciences, in order to approach and present scientific issues in an innovative way, through self-improvement, team-work, interaction, collaboration and discussion. It seems that SRBW was a learning experience regarding the critical awareness of transformative learning and changes in thinking and/or action in the field of Biosciences for the participating students, who worked using self-regulating learning, a strategy in which they took control of their learning through team building and active learning processes, exploring alternative ways of collaborating, deepening and presenting and, in general, understanding their scientific knowledge and their role within their curricula. Therefore, through self-directed learning, they chose to leave their comfort zone mostly by integrating new concepts of learning into their mental models, thus engaged in critical reflection and led to a radically innovative learning model in Biosciences.

The findings of this small scale research showed us that learning is essentially the process of interpreting an experience that affects the subsequent action of the individual, since values, perceptions, thoughts and feelings are determined, to a significant extent, by the reflection on 
our habits and assumptions, which are at the same time the limits of our perception, as Mezirow (1990) underlined. This experience offered the students the opportunity to approach university learning through a self-regulated, alternative, innovative strategy, leading to integrative, synthetic approaches grounded in team work, innovation and engagement in activities encouraging problem solving. Concluding, this initiative seemed to generate to a cognitive struggle, a concept identified as the engine that drives highly creative thinking since knowledge, skills and concepts are acquired and mental models are subsequently transformed, a process Mezirow referred to as transformative learning (Pennington, et al, 2013).

The recording of the views of the students who participated in the SRBW educational project resulted in the building of a "fresh" concept for knowledge, cooperation, self-management of educational activities. It was indeed a learning experience which, apart from cognitive and emotional dimensions, created conditions of transforming learning. It seems that this experience deeply moved them and left them with the feeling that learning could be viewed 'out of the box', that they can think and act autonomously, in creative ways, different than the ones they had followed before this learning experience.

Was this project a real transformative experience for students? Or it's just a chance -and a reason- for creating critically thoughtful thinking and re-imaging of mental schemes with respect to the essence of learning? It is perhaps about the "bursting" of some young, restless and creative young people who, through the self-managed learning experience of SRBW, laid the foundation in their biography for a critical and reflective learning. And what about faculty's role? Do we teach for transformation, as McGonigal (2007) asked? Finally, I would dare to say that SRBW triggered what Dirkx (2001) noted, an experience that fostered radical shifts in our consciousness, a personally relevant learning experience, deeply emotional, which woke up our feelings, such as joy, wonder, and pride.

\section{Acknowledgements}

All the credits are reserved for the students of the MBG Dept who participated in the SRBW and shared their reflections in order this research to be carried out.

\section{References}

Ambrose, S., Bridges, M., DiPietro, M., Lovett, M., \& Norman, M. (2010). How learning works. 7 Research-Based Principles for Smart Teaching. San Francisco: Jossey-Bass.

Andresen, L., Boud, D., \& Cohen, R. (2001). Experience-Based Learning. In G. Foley, (Ed.), Understanding Adult Education and Training, pp 225-239. Sydney: Allen \& Unwin.

Atkinson, R. (1998). The life story interview. Sage University Papers on Qualitative Research Methods. Thousand Oaks, CA: Sage. https://doi.org/10.4135/9781412986205

Bissell, N. A., \& Lemons, P. P. (2006). A New Method for Assessing Critical Thinking in the Classroom. BioScience, 66-72. https://doi.org/10.1641/0006-3568(2006)056[0066:ANMFAC]2.0.CO;2

Brookfield, S. D. (1986). Understanding and facilitating adult learning. San Francisco, CA: 
Jossey-Bass.

Brookfield, S. D. (2000). Adult Cognition as a Dimension of Lifelong Learning. In, J. Field, \& M. Leicester (Eds.), Lifelong Learning: Education Across the Lifespan (pp 89-101). London: RoutledgeFarmer.

Clark, M. C. (1993). Transformational Learning. In S. B. Merriam (Ed.), An update on adult learning theory. San Francisco: Jossey-Bass.

Cranton, P., \& King, P. K. (2003). Transformative learning as a professional goal. New Directions for Adult and Continuing Education, 98, 31-37. https://doi.org/10.1002/ace.97

Cranton, P. (1994). Understanding and promoting transformative learning: a guide for educators of adults. San Francisco: Jossey-Bass.

Cranton, P. (2013). Teaching for Transformation. Adult Education, 30, 27-32 (in Greek).

Cullen, J., Bloemker, G., Wyatt, J \& Walsh, M. (2017). Teaching a Social and Emotional Learning Curriculum: Transformative Learning through the Parallel Process. International Journal of Higher Education, 6(6), 163-169. https://doi.org/10.5430/ijhe.v6n6p163

Dirkx, J., \& Mezirow, J. (2006). Musings and Reflections on the Meaning, Context, and Process of Transformative Learning. A Dialogue Between John M. Dirkx and Jack Mezirow. Journal of Transformative Education, 4(2), 123-139. Sage Publications. https://doi.org/10.1177/1541344606287503

Dirkx, J. (2001). An Enduring and Expanding Legacy. Journal of Transformative Education, 9(3), 139-142. https://doi.org/10.1177/1541344612444774

Fraser, S. P. (2015). Transformative Science Teaching in Higher Education. Journal of Transformative Education, 13(2), 140-160. https://doi.org/10.1177/1541344615571417

Hamlin, M. (2015). Technology in Transformative Learning Environments. In: M. Hamlin, Transformative Curriculum Design in Health Sciences Education, 126-140. https://doi.org/10.4018/978-1-4666-8571-0.ch004

Hunter, J. W. (2012). Collective disorienting dilemmas: A "wikid" approach to fostering adult learning. College Quarterly, 15(2). Retrieved from https://files.eric.ed.gov/fulltext/EJ979428.pdf

Illeris, K. (2014). Transformative Learning and identity. London: Routledge.

Illeris, K. (2015). Transformative learning in higher education. Journal of Transformative Learning, 3(1), 46-51.

Jarvis P. (2004) Continuing Education and Training: Theory and Practice. Athens: Metaichmio (in Greek).

Kegan, R. (1994). In our heads: The mental demands of modern life. Cambrigde, MA: Harvard University Press. 
Kegan, R. (2000). What form transforms? In J. Mezirow, (Ed.), Learning as transformation (pp. 56-72). San Francisco, CA: Jossey-Bass.

Kong, S. C. (2015). An experience of a three-year study on the development of critical thinking skills in flipped secondary classrooms with pedagogical and technological support. Computers \& Education, 89, 16-31. https://doi.org/10.1016/j.compedu.2015.08.017

Kroth, M., \& Boverie, P. (2009). Using the Discovering Model to Facilitate Transformational Learning and Career Development. Journal of Adult Education, 38(1), 43-47. 2009.

Kyriazi, N. (1998). Sociological research - Critical review of methods and techniques. Athens: Greek Scientific Publications (in Greek).

McGonigal, K. (2007). Teaching for transformation: From learning theory to didactical strategies. Adult Education, 12, 12-15 (In Greek).

Merriam, S. B. (2004). The role of cognitive development in Mezirow's transformational learning theory. Adult Education Quarterly, 55(1), 60-68. https://doi.org/10.1177/0741713604268891

Mezirow, J. (1978). Perspective transformation. Adult Education, 28, 100-110. https://doi.org/10.1177/074171367802800202

Mezirow, J. (1990). Fostering Critical Reflection in Adulthood. San Francisco: Jossey-Bass.

Mezirow, J. (1997). Transformative learning: Theory to practice. New Directions for Adult \& Continuing Education, 74, 5-12. https://doi.org/10.1002/ace.7401

Mezirow, J. (2000). Learning as Transformation: Critical Perspectives on a Theory in Progress. The Jossey-Bass Higher and Adult Education Series.

Mezirow, J. (2009). An Overview on Transformation Learning. In: K. Illeris, (Ed), Contemporary Theories of Learning (pp. 90-105). London and New York: Routledge. Retrieved from https://pdfs.semanticscholar.org/1085/b8aaeee9d65dccbe930dca5fe6034bbaeb4d.pdf

Newman, M. (2012). Calling Transformative Learning Into Question: Some Mutinous Thoughts. Adult Education Quarterly, 62(1), 36-55. https://doi.org/10.1177/0741713610392768

Nohl, A. (2015). Typical Phases of Transformative Learning: A Practice-Based Model. Adult Education Quarterly, 65(1), 35-49. https://doi.org/10.1177/0741713614558582.

Pennington, D. D., Simpson, L. G., McConnell, S. M., Fair, M. J., \& Baker, J. R. (2013). Transdisciplinary Research, Transformative Learning and Transformative Science. BioScience, 63(7), 564-573. https://doi.org/10.1525/bio.2013.63.7.9

Pintrich, R. P., \& De Groot, V. E. (1990). Motivational and Self-Regulated Learning Components of Classroom Academic Performance. Journal of Educational Psychology, 82(1), 33-40. https://doi.org/10.1037/0022-0663.82.1.33 


\section{Macrothink}

International Journal of Learning and Development

ISSN 2164-4063 2018, Vol. 8, No. 3

Schraw, G., Crippen, K. J., \& Hartley, K. (2006). Promoting self-regulation in science education: Metacognition as part of a broader perspective on learning. Research in Science Education, 36(1-2), 111-139. https://doi.org/10.1007/s11165-005-3917-8

Stafford, T. (2012). The Essence of Transformational Adult Learning. Retrieved from https://elearningindustry.com/the-essence-of-transformational-adult-learning

Verma, G., \& Mallick, K. (2004). Educational research (Transl. E. Griva). Athens: Tipothito (in Greek).

Y1lmaz, Öz. (2017). Science Teacher Candidates' Learning and Studying Strategies in the Context of Self-regulation. International Journal of Higher Education, 6(4), 161-172. https://doi.org/10.5430/ijhe.v6n4p161

White, K. S. \& Nitkin, R. M. (2014). Creating a Transformational Learning Experience: Immersing Students in an Intensive Interdisciplinary Learning Environment, International Journal for the Scholarship of Teaching and Learning, 8(2), Article 3. https://doi.org/10.20429/ijsotl.2014.080203.

Zimmerman, B. J. (2008). Investigating self -regulation and motivation: Historical background, methodological developments, and future prospects. American Educational Research Journal, 45(1), 166-183. https://doi.org/10.3102/0002831207312909

\section{Copyright Disclaimer}

Copyright for this article is retained by the author(s), with first publication rights granted to the journal.

This is an open-access article distributed under the terms and conditions of the Creative Commons Attribution license (http://creativecommons.org/licenses/by/4.0/). 